DOI 10. 18307/2017. 0524

(C) 2017 by Journal of Lake Sciences

\title{
青海湖布哈河口区表层沉积物有机质分析及其比较沉积学意义”
}

\author{
魏亚琼 ${ }^{1}$, 王昌勇 ${ }^{1 * *}$, 孟祥豪 ${ }^{1}$, 刘文武 ${ }^{2}$, 周 毅 ${ }^{1}$, 常海亮 ${ }^{1}$ \\ ( 1 : 成都理工大学沉积地质研究院油气藏地质及开发工程国家重点实验室,成都 610051) \\ (2: 宜宾学院化学与化工学院,宜宾 644000)
}

\begin{abstract}
摘 要: 青海湖布哈河口区与晚三叠世鄂尔多斯盆地及四川盆地具有相似的古地理特征和水体环境,对布哈河口区表层 沉积物中有机质的类型和丰度进行研究具有重要的比较沉积学意义. 通过对布哈河口区河流、三角洲平原、前三角洲、滨 湖、浅湖及半深湖环境表层沉积物样品全岩组分、总有机碳 (TOC) 及有机质类型进行分析, 确定布哈河口区表层沉积物 中有机质主要为 $I_{2}{ }_{2}$ 型和少量 II ${ }_{1}$ 型, TOC 含量不超过 $4.29 \%$, 其中半深湖 TOC 含量最高并且有机质类型较好. 布哈河口 区表层沉积物中 TOC 含量主要受秥土矿物含量、有机质生产力和水深控制, 半深湖沉积物具有较高的黏土矿物含量、较 高的有机质生产力、较好的有机质类型和较大的覆水深度, 有利于有机质的生产和保存, 为河口区最有利于烃源岩发育 的环境. 同时, 根据前三角洲、浅湖及半深湖沉积物中 TOC 含量与水深存在良好的相关性, 建立了利用岩石中 TOC 含量 对古水深进行恢复的公式
\end{abstract}

关键词: 有机碳; 干酪根; 现代沉积; 布哈河口; 青海湖

\section{Organic matter analysis of surface sediment in Buha Estuary region and its comparative sedimentology significance}

\author{
WEI Yaqiong ${ }^{1}$, WANG Changyong ${ }^{1 * *}$, MENG Xianghao ${ }^{1}$, LIU Wenwu ${ }^{2}$, ZHOU Yi $^{1}$ \& CHANG Hailiang ${ }^{1}$ \\ (1: State Key Laboratory of Oil and Gas Reservoir Geology and Exploitation, Institute of Sedimentary Geology, Chengdu Uni- \\ versity of Technology, Chengdu 610051, P.R.China) \\ (2: School of Chemistry and Chemical Engineering, Yibin College, Yibin 644000, P.R.China)
}

\begin{abstract}
The paleogeography characteristics and water environment of Buha Estuary in Lake Qinghai are similar with those in Ordos Basin and Sichuan Basin in the Late Triassic. The study on the types of organic matter and its abundance in the surface sediment from Buha Estuary is significant to comparative sedimentology. The sediments were collected from river, prodelta, lakeshore, shallow lake and semi-deep lake in Buha Estuary region and were analyzed in aspects of whole-rock composition analysis, total organic carbon (TOC) and examination of the kerogen. The results demonstrate that $\mathrm{II}_{2}$ kerogen is the major organic matter type in sediments and only a few II $_{1}$ kerogen exist. TOC content in the sediments is no more than $4.29 \%$, and the samples collected from semi-deep lake generally have high TOC content while the quality of organic matter is better than that of the other places. The clay minerals content in sediments, organic matter productivity and water depth are the major factors that affect the TOC content in the sediments of Buha Estuary. The semi-deep lake is a sedimentary environment which was the most favorable hydrocarbon source place because of its high productivity and good condition for organic matter. At the same time, according to the good correlation between the water depth and TOC contents in sediments gathering from prodelta, shallow lake and semi-deep lake, the formula using the TOC contents has been established for reconstructing water depth.
\end{abstract}

Keywords: Organic carbon; kerogen; modern sediments; Buha Estuary region; Lake Qinghai

总有机碳 (TOC) 是指存在于岩石或沉积物内部有机质中的碳的含量, 通常以岩石或沉积物的质量百分

* 国家自然科学基金项目 (41302088) 资助. 2016-09-21 收稿; 2016-12-12 收修改稿. 魏亚琼(1992 ), 女, 硕士 研究生; E-mail: 1031066535@ qq.com.

** 通信作者; E-mail: wangchangyong09@ cdut.cn. 
比来表示, 是烃源岩划分和评价的重要指标之一 ${ }^{[1]}$. 以往多认为大型淡水湖泊是陆相优质烃源岩形成的有 利环境, 然而, 越来越多的证据表明, 烃源岩的发育和沉积水体盐度可能存在密切联系 ${ }^{[2-5]}$, 咸化湖盆甚至盐 湖也能够发育有效烃源岩和优质烃源岩 ${ }^{[6-7]}$. 我国不少陆相含油气盆地, 如晚三叠世的鄂尔多斯盆地和四川 盆地, 均发育咸化湖泊一三角洲沉积体系 ${ }^{[8-11]}$, 这一沉积体系中有利于烃源岩的发育环境是一个值得研究的 重要问题, 而对于古湖泊岩相古地理研究而言,古水深的恢复也同样重要. 本文主要对青海湖布哈河口区表 层沉积物中有机质特征及含量进行研究, 对有利的烃源岩发育环境进行分析, 同时在研究中发现沉积物中 TOC 含量与覆水深度存在良好的相关性, 表明沉积物中 TOC 含量可作为古水深恢复的一种有效手段. 因此, 对现代咸化湖泊及河口区沉积物中 TOC 含量及其分布特征进行研究, 不仅对于深化陆相湖盆生油岩地质认 识, 同时对于古环境研究和古水深恢复均有重要的比较沉积学意义.

\section{1 研究区域地质背景}

青海湖是我国内陆最大的咸水湖,位于青藏高原东北部, 海拔约 $3200 \mathrm{~m}$, 湖泊近似菱形, 由西北向东南 方向延伸, 西北部较高, 目前湖泊面积约 $4432.32 \mathrm{~km}^{2[12]}$, 最大水深 $28.7 \mathrm{~m}$, 平均水深约 $18.4 \mathrm{~m}^{[13]}$. 青海湖形 成于第三纪 ${ }^{[14]}$, 构造上处于南祁连槽向斜、南祁连槽背斜以及青海南山槽向斜三者中间, 是一个不对称地堑 式断陷湖泊 ${ }^{[15]}$ (图 1), 属于青海湖一共和内外流湖区, 晚更新世青海湖由外流湖变为内流湖 ${ }^{[16]}$, 由于气候转 冷青海湖现处于萎缩阶段 ${ }^{[17]}$.

青海湖在地形上是封闭的, 但是在水文地质意义上却是开放的, 湖盆周缘物源及出露地层控制了青海 湖的最终卤水类型为 $\mathrm{Na}(\mathrm{K})-\mathrm{Cl}$ 型 ${ }^{[18]}$. 青海湖湖区周缘发育 40 条大小河流, 其中布哈河最大, 提供了青海湖 人湖总径流量的 $67 \%{ }^{[19]}$, 布哈河携带大量的泥沙分别在鸟岛两侧人湖处形成三角洲, 地理坐标为 $36^{\circ} 55^{\prime} \sim$ $37^{\circ} 02^{\prime} \mathrm{N}, 99^{\circ} 50^{\prime} \sim 99^{\circ} 55^{\prime} \mathrm{E}$ 的布哈河口区为本文研究区 (图 2).

\section{2 有机碳特征及分析方法}

本次研究样品全部采自鸟岛两侧的布哈河口区,包括河道( D67)、滨湖 (D1～D16)、浅湖 (D32～D45)、 半深湖 (D46 D49)、三角洲平原 (D50 D 66) 及前三角洲 (D17 D31) 等沉积环境的表层沉积物样品 (图 2), 同时现场测量沉积物上覆水体盐度 (使用仪器为 Eutech COND610, 新加坡制造, 盐度测量范围为 $0.770 \sim 80$ $\mathrm{ng} / \mathrm{L}$ ), 测得采样点上覆水体盐度范围为 $0.01 \% 0$ 18.4\% . 采集的表层沉积物样品首先在实验室中剔除新鲜 植物, 然后放人烘箱中在 $102^{\circ} \mathrm{C}$ 恒温条件下烘 $24 \mathrm{~h}$, 制备后的样品研磨至 220 目 ( $\left.<77 \mu \mathrm{m}\right)$, 分别进行 X-胻射 全岩分析、TOC 分析及干酪根类型分析.

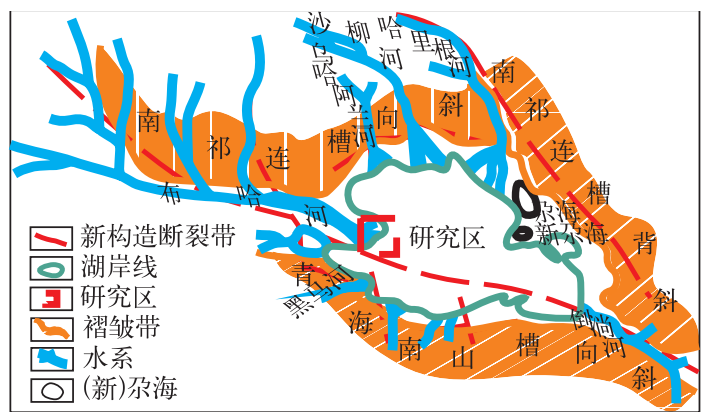

图 1 青海湖新构造略图( 根据文献 [15]修改)

Fig.1 Outlines of new structures of Lake Qinghai ${ }^{[15]}$

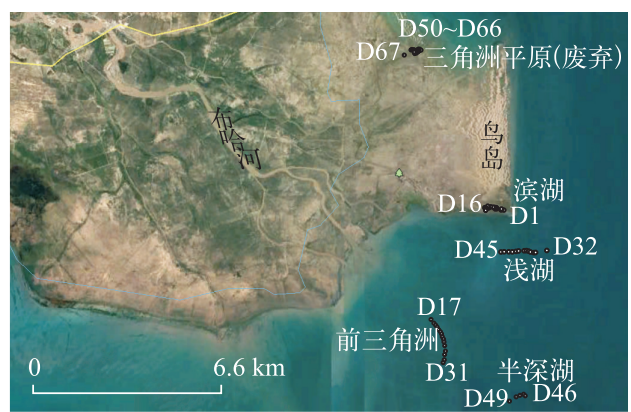

图 2 布哈河口区采样位置

Fig.2 Location of speciments in Buha River

其中, X-衍射全岩分析在 Rigaku D/max-IIIc 衍射仪上进行, 铁片滤光, Co 靶 K $\alpha$ 射线, 工作电压 $40 \mathrm{kV}$ 、 电流 $30 \mathrm{~mA}$, 光阑系统为: $\mathrm{DS}($ 发散狭缝 $)=\mathrm{SS}($ 防散射狭缝 $)=1^{\circ}, \operatorname{RS}($ 接受狭缝 $)=0.3 \mathrm{~mm}$, 扫描范围 $3^{\circ} \sim$ $50^{\circ}$, 步长 $0.04^{\circ}$, 计数时间为 $0.4 \mathrm{~s}$, 实验数据的处理参考文献 [19]. TOC 含量分析在 leco-cs 230 碳硫分析仪 上进行, 首先称取 $1 \mathrm{~g}$ 样品放人可渗水的陶瓷坩埚, 称重并记录, 然后向坩埚中缓慢滴人 $3 \%$ (重量比) 的稀 
盐酸直到不再有气泡逸出, 再用去离子水缓慢滴人坩埚, 反复清洗余样, 然后将坩埚放人烤箱在 $80^{\circ} \mathrm{C}$ 条件下 烘干, 再次称重并记录, 然后将烘干后的坩埚连同样品放人碳硫分析仪进行分析, 记录实验结果并计算有机 碳含量,其相对误差 $<5 \%$. 干酪根分离制备参考文献 $[20]$,样品分离后进行镜检分析.

\section{1 布哈河口总有机碳特征}

青海湖布哈河口区不同沉积环境表层沉积物中有机碳的含量存在较大差异: 来自半深湖及前三角洲表 层沉积物样品一般具有较高的 TOC 含量, 其中半深湖沉积物中的 TOC 含量介于 $1.38 \% \sim 1.94 \%$ 之间, 平均 TOC 含量为 $1.75 \%$; 前三角洲沉积物中的 TOC 含量介于 $1.06 \% \sim 1.54 \%$ 之间, 平均值为 $1.29 \%$; 滨湖沉积物中 TOC 含量介于 $0.40 \% \sim 4.29 \%$ 之间, 平均值可达 $1.15 \%$; 三角洲平原沉积物中 TOC 含量极少超过 $1 \%$, 其平均 值仅为 $0.37 \%$; 浅湖及布哈河古道沉积物中的 TOC 含量极低,一般介于 $0.29 \% \sim 0.66 \%$ 之间(表 1 ).

表 1 布哈河口沉积物中 TOC 含量、水体盐度及采样水深

Tab.1 TOC content in sediments, salinity in water and water depth of Buha River estuary

\begin{tabular}{|c|c|c|c|c|c|c|c|}
\hline \multirow{2}{*}{ 环境 } & \multirow{2}{*}{ 样品数量 } & \multicolumn{2}{|c|}{ 水深 $/ \mathrm{m}$} & \multicolumn{2}{|c|}{ TOC/\% } & \multicolumn{2}{|c|}{ 盐度/\%o } \\
\hline & & 范围 & 平均值 & 范围 & 平均值 & 范围 & 平均值 \\
\hline 滨湖 & 16 & - & - & $0.40 \sim 4.29$ & 1.15 & $3.21 \sim 18.03$ & 9.29 \\
\hline 浅湖 & 13 & $5.5 \sim 10.0$ & 7.65 & $0.29 \sim 0.66$ & 0.48 & $11.54 \sim 12.03$ & 11.76 \\
\hline 半深湖 & 5 & $18.0 \sim 19.5$ & 18.6 & $1.38 \sim 1.94$ & 1.75 & $11.87 \sim 12.09$ & 11.94 \\
\hline 前三角洲 & 15 & $11.0 \sim 13.8$ & 12.33 & $1.06 \sim 1.54$ & 1.29 & $11.12 \sim 11.90$ & 11.62 \\
\hline 三角洲平原 & 17 & - & - & $0.06 \sim 1.24$ & 0.37 & $1.22 \sim 11.03$ & 7.85 \\
\hline 布哈河古道 & 1 & - & - & \multicolumn{2}{|c|}{0.61} & \multicolumn{2}{|c|}{0.0716} \\
\hline
\end{tabular}

布哈河口地区除滨湖以外, 表层沉积物总体上表现为由浅向深 TOC 含量逐渐增大的趋势, 即: 浅湖区及 三角洲平原较低, 前三角洲与半深湖沉积物 TOC 含量较高. 同时, 滨湖及三角洲平原沉积物中 TOC 含量变 化较大, 两者在位置上位于湖平面以上, 受生物活动影响较大. 如滨湖沉积物样品 D10, 其沉积物样品中的 TOC 含量高达 $4.29 \%$, 常量元素分析结果显示其具有较高的磷含量 $\left(\mathrm{P}_{2} \mathrm{O}_{5}\right.$ 含量约 $\left.0.2 \%\right)$, 与鸟粪土成分相 似 ${ }^{[21]}$, 同时其 $\mathrm{Mg} / \mathrm{Ca}$ 比值约为 $0.3,550^{\circ} \mathrm{C}$ 烧失量 $\left(\mathrm{LOI}_{550 \% \mathrm{C}}\right)$ 可达 $23 \%$, 其常量元素组成与牛粪相似 ${ }^{[22]}$, 反映 该样品可能兼有鸟类和牲畜的贡献, 这一结果与采样位置大量活动的鸟类和发现的牛蹄印迹相吻合. 需要 说明的是, 浅湖区虽然生物含量远高于半深湖区, 但生物遗体多被湖流搬运至半深湖一深湖区保存 ${ }^{[23]}$, 可能 是导致浅湖沉积物中 TOC 含量较低的主要原因.

\section{2 有机质特征及来源}

干酪根定义为:一切不溶于常用有机溶剂的沉积有机质 ${ }^{[24]}$, 包含了沉积物中的年青干酪根. 沉积物中 的有机质主要来源于干酪根, 其类型基本不会在成岩作用中发生改变, 因此干酪根可以很好地表征成油母 质的类型 ${ }^{[25]}$.

本次研究随机选取了滨湖、浅湖、半深湖、三角洲平原及前三角洲环境共计 10 件样品进行干酪根的分 离和镜检, 确定布哈河口区类型主要为 $I_{1}$ 和 II ${ }_{2}$ 型, 有机质主要来源于高等植物或其生物降解产物, 大部分 为陆源生物贡献, 少量由水生生物贡献. 不同环境的表层沉积物中有机显微组分具有以下特征: 腐泥组三角 洲平原沉积物中含量极低,一般不超过 $10 \%$, 而前三角洲、滨湖、浅湖及半深湖沉积物中含量稍高,一般大于 $12 \%$, 其中半深湖区可达 $36 \%$; 壳质组在三角洲平原沉积物中最高, 可达 $71 \%$, 而在半深湖相对较低, 可低至 $47 \%$; 镜质组及惰质组相带分异性不明显, 但惰质组含量相对较高的样品主要来源于三角洲平原环境(表 2).

\section{3 有机质丰度的控制因素}

影响有机质丰度的因素既包括水流速度、黏土矿物含量、波浪作用及沉积速率等沉积水体的物理因素, 也包括氧化还原电位 ( $\mathrm{Eh}$ 值)、酸碱度 ( $\mathrm{pH}$ 值)、盐度和温度等化学因素, 同时还受到生物及生物化学活动等 生物因素 ${ }^{[26]}$. 布哈河口区沉积环境较为复杂, 不同沉积环境覆水深度、沉积物组分及有机质初产率等均存 在明显差异,沉积物中有机碳的含量主要受到这些因素的影响和控制. 
表 2 布哈河口区表层沉积物干酪根类型及其显微组分特征

Tab.2 Kerogen types and maceral characteristics of the surface sediments in Buha River estuary

\begin{tabular}{|c|c|c|c|c|c|c|c|c|c|c|c|c|c|c|c|c|c|c|}
\hline \multirow[b]{2}{*}{ 样品编号 } & \multirow[b]{2}{*}{ 环境 } & \multicolumn{3}{|c|}{ 腐泥组/\% } & \multicolumn{8}{|c|}{ 壳质组/\% } & \multicolumn{3}{|c|}{ 镜质组 $/ \%$} & \multirow{2}{*}{$\begin{array}{l}\begin{array}{l}\text { 惰质 } \\
\text { 组 } \%\end{array} \\
\text { 丝 } \\
\text { 质 }\end{array}$} & \multicolumn{2}{|c|}{ 类型 } \\
\hline & & $\begin{array}{l}\text { 浮 } \\
\text { 游 } \\
\text { 澡 } \\
\text { 类 }\end{array}$ & $\begin{array}{l}\text { 腐 } \\
\text { 泥 } \\
\text { 组 } \\
\text { 定 } \\
\text { 形 } \\
\text { 体 }\end{array}$ & 小 & $\begin{array}{l}\text { 角 } \\
\text { 质 } \\
\text { 体 }\end{array}$ & $\begin{array}{l}\text { 木 } \\
\text { 栓 } \\
\text { 质 } \\
\text { 体 }\end{array}$ & $\begin{array}{l}\text { 树 } \\
\text { 脂 } \\
\text { 体 }\end{array}$ & $\begin{array}{l}\text { 孢 } \\
\text { 粉 } \\
\text { 体 }\end{array}$ & $\begin{array}{l}\text { 腐 } \\
\text { 殖 } \\
\text { 定 } \\
\text { 形 } \\
\text { 体 }\end{array}$ & $\begin{array}{l}\text { 菌 } \\
\text { 狍 } \\
\text { 体 }\end{array}$ & $\begin{array}{l}\text { 底 } \\
\text { 栖 } \\
\text { 藻 } \\
\text { 定 } \\
\text { 形 } \\
\text { 体 }\end{array}$ & $\begin{array}{l}\text { 小 } \\
\text { 计 }\end{array}$ & $\begin{array}{l}\text { 富 } \\
\text { 空 } \\
\text { 镜 } \\
\text { 质 } \\
\text { 体 }\end{array}$ & $\begin{array}{l}\text { 正 } \\
\text { 常 } \\
\text { 镜 } \\
\text { 质 } \\
\text { 体 }\end{array}$ & 小 & & $\begin{array}{l}\text { 类 } \\
\text { 型 } \\
\text { 指 } \\
\text { 数 } \\
\Xi\end{array}$ & $\begin{array}{l}\text { 类 } \\
\text { 型 }\end{array}$ \\
\hline D04 & 滨湖 & - & 14 & 14 & 3 & 16 & 17 & 2 & 2 & 29 & - & 69 & 3 & 12 & 15 & 2 & 39.3 & $\mathrm{II}_{2}$ \\
\hline D11 & & - & 16 & 16 & 4 & 13 & 16 & 4 & 3 & 22 & - & 62 & 5 & 14 & 19 & 3 & 36.0 & $\mathrm{II}_{2}$ \\
\hline D18 & 前三角洲 & 3 & 14 & 17 & 4 & 9 & 19 & 2 & 3 & 27 & - & 64 & 4 & 11 & 15 & 4 & 39.2 & $\mathrm{II}_{2}$ \\
\hline D31 & & 4 & 13 & 17 & 4 & 10 & 18 & 4 & 4 & 24 & - & 64 & 2 & 14 & 16 & 3 & 37.7 & $\mathrm{II}_{2}$ \\
\hline D39 & 浅湖 & - & 26 & 26 & - & - & 34 & - & - & 29 & - & 63 & - & 9 & 9 & 2 & 48.8 & $\mathrm{II}_{1}$ \\
\hline D43 & & - & 14 & 14 & - & 8 & 29 & - & - & 24 & - & 61 & 8 & 12 & 20 & 5 & 31.3 & $\mathrm{II}_{2}$ \\
\hline D47 & 半深湖 & 8 & 28 & 36 & - & 4 & 20 & 2 & 2 & 19 & - & 47 & 4 & 10 & 14 & 3 & 49.4 & $\mathrm{II}_{1}$ \\
\hline D49 & & - & 12 & 12 & - & 14 & 23 & 4 & 2 & 22 & - & 65 & 4 & 15 & 19 & 4 & 29.7 & $\mathrm{II}_{2}$ \\
\hline D55 & 三角洲平原 & - & 8 & 8 & 4 & 16 & 22 & 4 & 2 & 19 & - & 67 & 5 & 14 & 19 & 6 & 27.5 & $\mathrm{II}_{2}$ \\
\hline D63 & & - & 4 & 4 & 8 & 15 & 25 & 6 & 4 & 13 & - & 71 & 6 & 15 & 21 & 4 & 28.9 & $\mathrm{II}_{2}$ \\
\hline
\end{tabular}

\section{1 沉积物组分的影响}

由于黏土矿物对有机质有明显的凝絮作用 ${ }^{[27]}$, 黏土矿物吸附有机质后可有效阻止生物对有机质的降 解 ${ }^{[28]}$. 因此,沉积物中黏土矿物含量对有机质的丰度 有明显的影响.

$\mathrm{X}$-衍射全岩分析结果 ( 表 3) 表明: 布哈河口区表 层沉积物中黏土矿物的含量总体偏低,一般不超过 $36 \%$; 布哈河河道、三角洲平原、滨湖及浅湖沉积物中 黏土矿物含量较低,一般不超过 $30 \%$, 平均值不超过 $20 \%$; 前三角洲及半深湖沉积物中黏土矿物含量相对 较高,一般不低于 $26 \%$,平均值 $>30 \%$. 大部分沉积环 境的表层沉积物中 TOC 含量与黏土矿物含量之间总 体存在较为明显的正相关性,其中, 三角洲平原、滨湖、 浅湖及半深湖环境样品的相关性最好,而采自前三角 洲环境的样品相关性相对较差 (图 3), 推测其原因主 要为前三角洲沉积受河流作用影响较大, 沉积速率较 高,沉积物中的有机质主要由泥沙携人,而鸟岛北部的 废弃三角洲平原及滨湖、浅湖和半深湖区域,沉积物中 的有机质主要依赖于黏土矿物原地的凝絮作用.

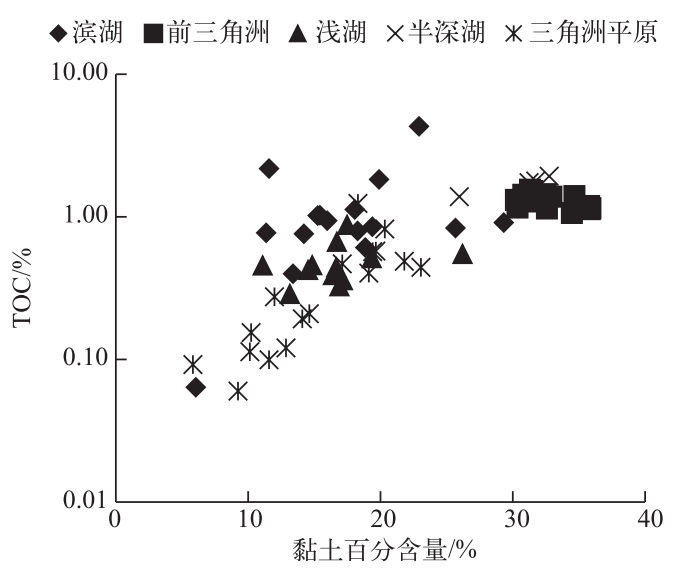

图 3 布哈河口沉积物中黍土矿物 百分含量与 TOC 含量的关系

Fig. 3 Clay mineral content as functions of TOC content in the sediments of Buha River estuary

\section{2 有机质生产力}

由于布哈河口区表层沉积物有机质的来源主要包括两大类, 即: 高等植物和低等生物菌类为主的陆源 生物以及低等菌藻类为主的水生生物. 布哈河口区滨湖及三角洲平原环境陆生植物极为繁盛 (图 4), 同时 有多种菌类生长, 这些高等植物和低等生物菌类死亡后能够提供大量有机质, 是滨湖及三角洲平原地区主 要的有机质来源, 同时动物活动对有机质的来源也有一定贡献, 特别是滨湖区鸟类等生物活动频繁, 其排泄 物可能导致局部有机质丰度异常高. 水生低等生物对布哈河口区表层沉积物有机质丰度有不同程度的贡 献, 青海湖及布哈河水体中浮游动物虽然较少, 但硅藻、甲藻、绿藻、蓝细菌等浮游植物数量较大 ${ }^{[29]}($ 表 4), 这些浮游生物死亡后成为河口区特别是浅湖和半深湖区有机质重要的来源. 
表 3 布哈河口区表层沉积物黏土矿物含量及 TOC/黏土比值 (OMP)

Tab.3 Clay mineral content and TOC/clay ratio in surface sediments of Buha River estuary

\begin{tabular}{cccccccc}
\hline & & 滨湖 & 浅湖 & 半深湖 & 前三角洲 & 三角洲平原 & 布哈河 \\
\hline \multirow{2}{*}{ 黏土 $/ \%$} & 范围 & $11 \sim 29$ & $11 \sim 26$ & $26 \sim 33$ & $30 \sim 36$ & $9 \sim 22$ & 20 \\
& 平均值 & 16.89 & 16.75 & 30.44 & 32.75 & 15.59 & \\
\multirow{2}{*}{ OMP } & 范围 & $2.95 \sim 18.71$ & $1.92 \sim 5.01$ & $5.30 \sim 5.87$ & $3.08 \sim 4.93$ & $0.64 \sim 6.74$ & 2.98 \\
& 平均值 & 6.64 & 2.91 & 5.58 & 3.97 & 2.23 & \\
\hline
\end{tabular}
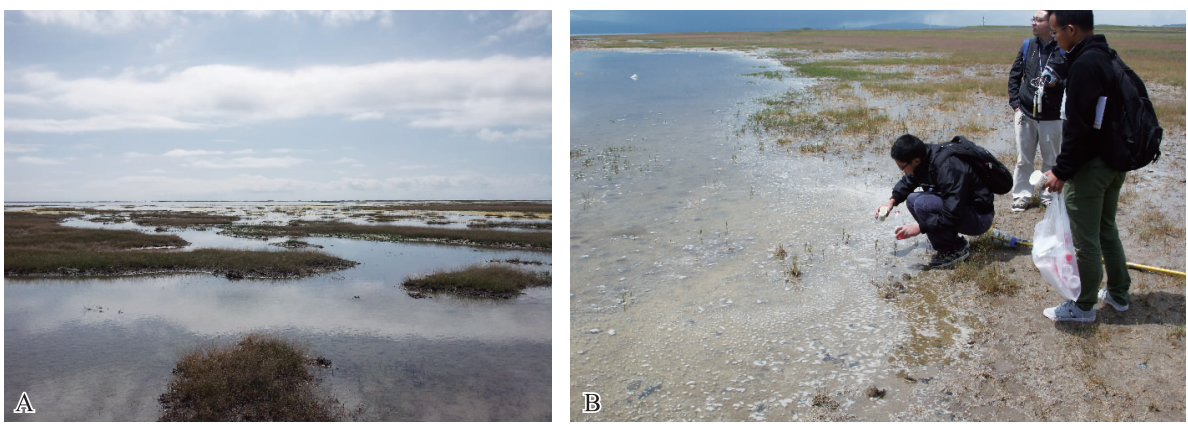

图 4 布哈河口区沉积环境特征

( A-滨湖环境, 植物繁盛,鸟类等生物活动强烈; B-三角洲平原,植物繁盛,偶有鸟类活动)

Fig.4 Characteristics of sedimentary environments of Buha River estuary

表 4 青海湖及布哈河水体浮游生物数量 (根据文献 [ 23] 修改)

Tab.4 The number of plankton in the water of Lake Qinghai and Buha River ${ }^{[23]}$

\begin{tabular}{|c|c|c|c|c|c|c|c|c|c|c|c|c|}
\hline \multirow{2}{*}{ 水体 } & \multicolumn{7}{|c|}{ 浮游植物/( cells/L) } & \multicolumn{5}{|c|}{ 浮游动物/(ind./L) } \\
\hline & 硅藻 & 甲藻 & 绿藻 & 蓝细菌 & 金藻 & 裸藻 & 合计 & 原生 & 氻物 轮虫 & & 自类 桡足类 & 合计 \\
\hline 青海湖 & 35476 & 13985 & 5619 & 721 & 3011 & 35 & 58847 & 387 & 12 & 1 & 17 & 418 \\
\hline 布哈河 & 1497100 & 0 & 6600 & 8800 & 0 & 0 & 1512500 & 0 & 0 & 0 & 1 & 1 \\
\hline
\end{tabular}

由于沉积物中 TOC 含量明显受到黏土矿物含量的影响(图 3), 因此沉积物中 TOC 含量可能无法真实衡 量其有机质的生产能力, 而仅仅只能反映不同环境沉积物对有机质凝絮能力的高低. 由于不同沉积环境黏 土矿物含量存在明显差别, 为此, 本文采用 TOC/黏土含量的比值 ( OMP) 间接推测不同环境有机质生产 (包 括输人) 能力的大小. 结果表明: 布哈河道、三角洲平原及浅湖环境 OMP 值介于 $0.64 \sim 6.74$ 之间, OMP 平均 值均低于 3 , 反映其有机质生产力均不高; 滨湖环境 OMP 平均值虽然高达 6.64 , 但不同采样位置的 OMP 值 差异太大, 反映其有机质生产力不稳定, 受偶然因素影响太大; 前三角洲环境 OMP 值介于 $3.04 \sim 4.93$ 之间, 平均值为 3.97 , 总体具有较高的有机质生产能力; 半深湖环境 OMP 值介于 $5.30 \sim 5.87$ 之间, 平均值为 5.58 , 具有相对最高的有机质生产力 (表 3 ).

\section{3 有机质保存条件}

由于本研究主要采集的河口区表层沉积物, 因此其有机碳含量只是暂时的状态,而最终有多少有机质能 够在地层中埋藏保留则主要取决于有机质的保存条件. 已有研究表明, 青海湖由于对流强烈, 水体缺乏明显分 层 (这一认识在本次研究野外考察过程中再次得到确认, 主要表现在同一采样位置不同深度水体盐度、pH 值 等参数的一致性). 虽然对流作用导致湖水中富氧, 但在距湖底几厘米之下仍然存在还原环境 ${ }^{[28]}$, 其中深湖区 甚至为强还原环境, Eh 值<-200 $\mathrm{mV}^{[29]}$, 总体具有随覆水深度增大环境还原条件逐渐增强的特征. 布哈河道、 三角洲平原及滨湖地区覆水较浅甚至间歇性暴露,最不利于有机质的保存; 浅湖环境水深一般不足 $10 \mathrm{~m}$, 波浪 
作用强烈, 水体富氧,也不利于有机质的保存; 前三角洲及半深湖环境水体较深,有利于有机质的保存.

\section{4 比较沉积学意义}

古代三角洲沉积体系是油气生成和聚集的有利环境, 特别是鄂尔多斯盆地上三叠统延长组以及四川盆 地上三叠统须家河组,发育一套咸化湖泊一三角洲沉积体系 ${ }^{[8-11]}$, 与青海湖布哈河三角洲可以进行类比, 因 此, 对布哈河口区表层沉积物有机质特征进行分析, 对深人了解咸化湖泊一三角洲沉积体系中有机质的来源 及烃源岩的发育特征具有十分重要的比较沉积学意义, 同时, 湖区采样水体深度与总有机碳含量之间存在 着良好的相关性,展现了在古地理研究方面的良好应用前景.

\section{1 有利烃源岩发育环境}

传统的烃源岩评价主要针对古代地层, 经过地质历史时期漫长的有机质热演化过程和排烃过程, 不同 沉积相带残余有机质的丰度必然不同程度地低于其原始值, 即基于现今残余 TOC 的烃源岩评价结果不一定 能够真实反映有利烃源岩发育环境, 因此, 本次基于现代沉积物中有机质特征分析, 对布哈河口区有利烃源 岩发育环境进行评价, 对于古代烃源岩评价具有重要的借鉴意义.

优质烃源岩的形成既需要丰富的有机质来源, 同时也需要良好的聚集与保存条件 ${ }^{[30]}$. 本次研究, 主要 根据有机质生产力、干酪根类型、覆水深度及有机质保存条件对布哈河口区不同沉积环境生烃能力进行定 性评价: 三角洲平原有机质生产力低, 干酪根主要为 $I_{2}{ }_{2}$ 型, 覆水深度极浅并间歇暴露, 有机质保存条件差, 生烃能力差; 浅湖有机质生产力低, 干酪根主要为 II $1_{1}$ 或 II ${ }_{2}$ 型, 覆水深度较浅, 波浪作用较强, 水体富氧, 有机 质保存条件较差, 生烃能力差; 滨湖有机质生产力较高, 干酪根主要为 II ${ }_{2}$ 型, 覆水深度极浅并间歇暴露, 有 机质保存条件差, 生烃能力较差; 前三角洲有机质生产力较高, 干酪根主要为 $I_{2}$ 型, 覆水深度较大, 有机质 保存条件较好, 生烃能力较好; 半深湖有机质生产力高, 干酪根主要为 II ${ }_{1}$ 或 II ${ }_{2}$ 型, 覆水深度大, 有机质保存 条件好, 生烃能力好 (表 5). 从评价结果看来前三角洲和半深湖环境生烃能力较好, 其中半深湖环境无论从 有机质生产力还是从干酷根类型来看都更甚一筹, 再加上更大的覆水深度和更好的保存条件, 为布哈河口 区最有利烃源岩发育的环境.

表 5 布哈河口区主要沉积环境生烃能力评价

Fig.5 Hydrocarbon potential evaluation of Buha River estuary

\begin{tabular}{cccccc}
\hline 评价指标 & 三角洲平原 & 前三角洲 & 滨湖 & 浅湖 & 半深湖 \\
\hline 有机质生产力 & 低 & 较高 & 较高 & 低 & 高 \\
干酪根类型 & $\mathrm{II}_{2}$ & $\mathrm{II}_{2}$ & $\mathrm{II}_{2}$ & $\mathrm{II}_{1}$ 或 $\mathrm{II}_{2}$ & $\mathrm{II}_{1}$ 或 $\mathrm{I}_{2}$ \\
覆水深度 $/ \mathrm{m}$ & $<0.5$ & $11 \sim 14$ & $<0.5$ & $6 \sim 10$ & $18 \sim 20$ \\
保存条件 & 差 & 较好 & 差 & 较差 & 好 \\
生烃能力 & 差 & 较好 & 较差 & 差 & 好 \\
\hline
\end{tabular}

\section{2 古水深恢复}

古水深恢复是古地貌研究的重要内容之一, 目前多根据介形虫 ${ }^{[31]}$ 、有孔虫、硅藻、孢子花粉等动植物分 布特征 ${ }^{[32]}$ 、伽马能谱测井信息 ${ }^{[33]}$ 、压实恢复 ${ }^{\left[{ }^{[} 4\right]}$ 以及特定环境形成的沉积构造、自生矿物、沉积物分布规律 等物理岩石记录 ${ }^{[35]}$ 的方法进行古水深恢复, 但由于各种成岩作用的影响, 其恢复难度较大, 且精确度较低.

本次研究发现, 青海湖布哈河口区湖岸线之下 (包括前三角洲、浅湖及半深湖) 的表层沉积物样品中 TOC 含量与采样深度 (水深) 之间存在良好的相关性 $(R=0.92)$, 即: 随着水体深度的增加, 沉积物粒度逐渐 变细、泥质含量的增多, TOC 含量亦逐渐升高 (图 5). 因此, 有机碳 TOC 含量可用于湖泊古水深恢复, 即水体 深度可由以下公式估算:

$$
H=5.6375 \mathrm{e}^{0.618 T O C_{0}}
$$

式中, $H$ 为水深 $(\mathrm{m}), T O C_{\mathrm{o}}$ 为原始有机碳总量 $(\%)$.

需要注意的是, 沉积岩中有机质经历过热演化和排烃, 其有机碳总量有不同程度的损失, 因此在利用公 式 (1) 进行古水深恢复时必须将 TOC 含量恢复至原始状态. 


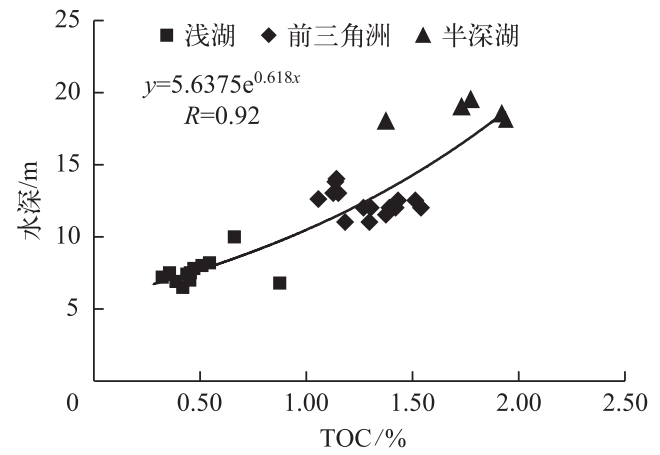

图 5 布哈河口区采样水深与 沉积物中 TOC 含量的关系

Fig.5 Sample depth as function of TOC content in the sediments of Buha River estuary
沉积岩中原始有机碳的恢复多以物质守恒原理为 基础, 通过计算总有机碳含量恢复系数 $(K c)$ 对原始有 机碳进行恢复, 即:

$$
T O C_{\mathrm{o}}=T O C_{\mathrm{r}} \cdot K c
$$

式中, $T O C_{\mathrm{r}}$ 为残余有机碳总量 $(\%)$.

有机碳恢复系数的计算方法很多,如热解模拟实验 法 $^{[36]}$ 、平衡反应模型 ${ }^{[37]}$ 、生烃动力学 ${ }^{[7,38]}$ 、无效碳守恒 法 $^{[39]}$ 、化学反应守恒法 ${ }^{[40-41]}$ 、有机质守恒法 ${ }^{[42-43]}$ 、MoTOC 法 ${ }^{[44]}$ 等, 本文主要引用卢双舫等 ${ }^{[42]}$ 提出的公式:

$$
K c=1 /(1-D T O C)
$$

式中, $D T O C$ 为有机碳损失率.

根据模拟实验获取岩石的排烃效率 ${ }^{[45-46]}$, 并结合干 酪根类型分析、成熟度分析结果, 可以在图 6 上估算出 DTOC 值, 考虑到成岩过程中可能带来的岩石质量的变 化, 有机碳恢复系数 $\left(K c^{\prime}\right)$ 能更客观地反映有机质丰度 的变化 ${ }^{[41]}$.

因此,利用岩石中 $T O C_{\mathrm{r}}$ 恢复古水深的公式为:

$$
H=5.6375 \mathrm{e}^{0.618 \mathrm{TOC}_{r} \cdot K \mathrm{c}^{\prime}}
$$

需要说明的是, 图 6 只给出了对应排烃效率分别为 $10 \% 、 30 \% 、 50 \% 、 70 \% 、 90 \%$ 的 $K c$ (或 $K c^{\prime}$ ) 曲线,估计 $K c$ (或 $K c^{\prime}$ ) 读数可能存在一定误差 (不超过 0.1 ), 会对古水深的恢复结果带来一定影响, 以 $T O C_{\mathrm{r}}$ 取值 $2 \%$, $K c$ (或 $K c^{\prime}$ ) 分别取值 1.7 和 1.6, 其古水深恢复结果差值仅 $5 \mathrm{~m}$ 左右, 因此, 本文提出的古水深预测公式适用 陆相湖盆地层古水深的恢复, 但其数据仅来自青海湖, 因不同湖盆生产力及有机质保存条件的差异, 对其他 类型的湖泊还需要进一步丰富数据, 研究修正, 以提高预测精度. 由于不同类型烃源岩的演化过程不同,同 时成岩作用的影响较为复杂, 该公式目前对咸化湖泊一三角洲沉积体系成熟度较低的烃源岩可能更为适用, 而对成熟度较高的烃源岩,古水深恢复公式仍有待于修正和验证.

\section{5 结论}

1) 布哈河口区表层沉积物中有机碳含量介于 $0.06 \% \sim 4.29 \%$, 其中半深湖有机碳含量最高, 其次为前三 角洲及滨湖沉积物, 三角洲平原及浅湖沉积物有机碳含量较低, 三角洲平原及滨湖沉积物由于间歇暴露, 受 动物活动影响较强而导致有机碳含量波动较大;

2) 布哈河口区有机质干酪根类型主要为 $I_{1}$ 和 $I_{2}$ 型, 大部分为陆源生物贡献, 少量由水生生物贡献, 腐 泥组分在浅湖及半深湖沉积中相对含量最高;

3)布哈河口区表层沉积物中有机质丰度较高, 主要受黏土矿物含量、有机质生产力和水深控制, 黏土矿 物含量越高、有机质生产力越强、水深越大,越有利于沉积物中有机质的保存;

4)布哈河口区表层沉积物中有机质分析具有重要的比较沉积学意义, 具有一定盐度的陆相湖盆河口区 半深湖环境最有利于烃源岩的发育, 同时,利用有机碳含量对古水深进行恢复具有很好的应用前景.

\section{6 参考文献}

[ 1 ] Zhang Houfu, Fang Chaoliang, Gao Xianzhi et al eds. Petroleum geology. Beijing: Petroleum Industry Press, 1999 : 1-50. [张厚福, 方朝亮, 高先智等. 石油地质学. 北京: 石油工业出版社, 1999: 1-50.]

[ 2 ] Li Renwei. Geological occurrence and its paleoenvironmental significance of gammacerane. Chinese Sci Bull, 1988, 20: 1574-1576. [李任伟. 伽马蜡烷的地质产状及古环境意义. 科学通报, 1988, 20: 1574-1576.]

[ 3 ] Miao Jianyu, Zhou Lifa, Deng Kun et al. Organic matters from middle Permian source rocks of northern Xinjiang and their relationships with sedimentary environments. Geochimica, 2004, 33(6): 551-560. [苗建宇, 周立发, 邓昆等. 新疆北 部中二叠统烃源岩有机质与沉积环境的关系. 地球化学, 2004, 33(6) : 551-560.] 


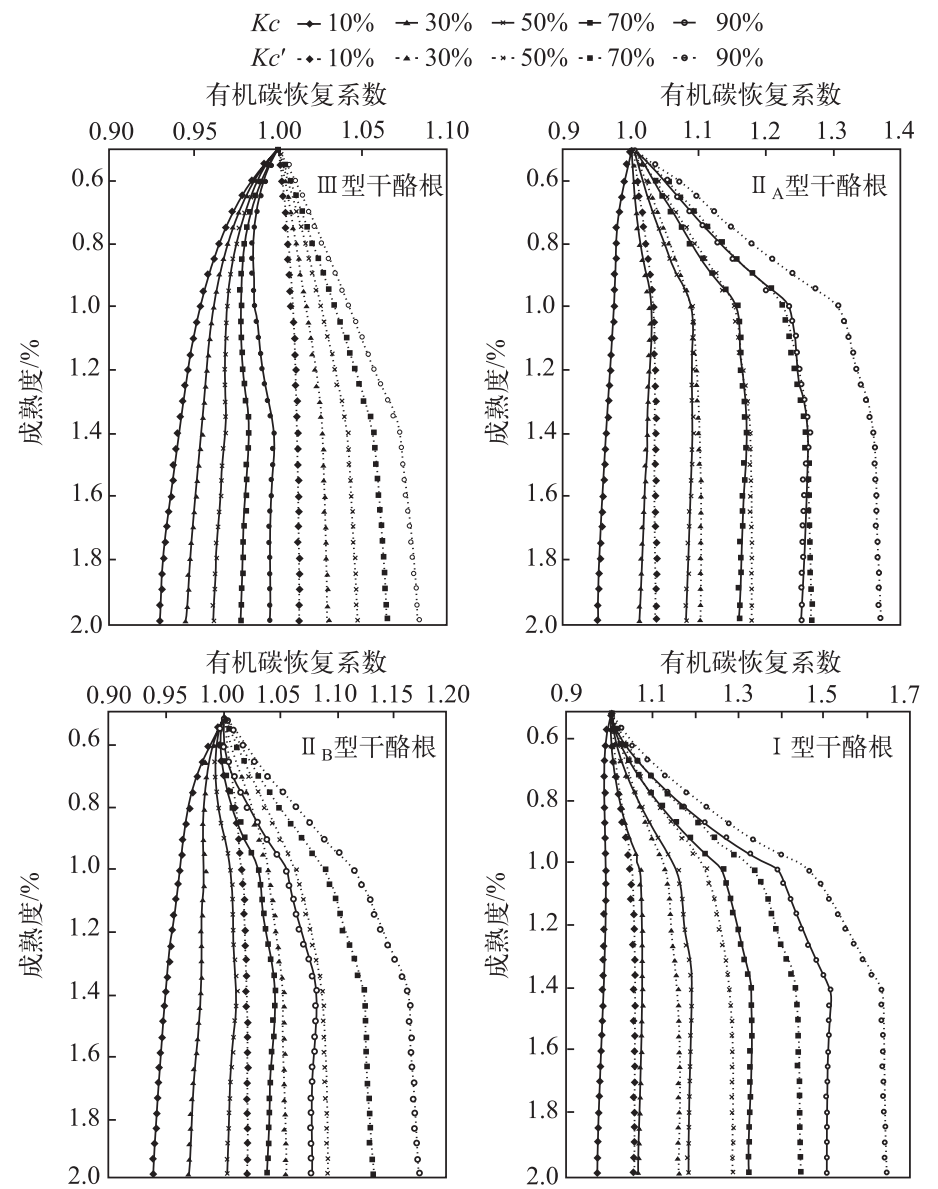

图 6 有机碳恢复系数 $\left(K c\right.$ 和 $\left.K c^{\prime}\right)$ 与成熟度、排烃效率和有机质类型的关系 ${ }^{[42]}$

Fig.6 Reconstruction coefficient of organic carbon vs. maturation, hydrocarbon expulsion efficiency and type of organic mater ${ }^{[42]}$

[ 4 ] Qian Huanju, Lu Xiancai, Zhang Xuefen et al. Spatial paleosalinity distribution and element geochemistry of argillaceous source rocks in the upper part of 4th Member of Tertiary Shahejie Formation in Dongying Sag. Acta Peirologica et Mineralogica, 2009, 28(2) : 161-168. [ 钱焕菊, 陆现彩, 张雪芬等. 东营凹陷沙四段上部泥质烃源岩元素地球化学及其 古盐度的空间差异性. 岩石矿物学杂志, 2009, 28(2): 161-168.]

[ 5 ] Cheng Mengjin, Ning Ning, Hu Guoyi et al. Characteristics and influencing factors of Pingliang Formation source rock in Western Ordos Basin. Chinese Science Bulletin, 2007, 52( supp I ) : 78-85. [ 陈孟晋, 宁宁, 胡国艺等. 鄂尔多斯盆地 西部平凉组烃源岩特征及其影响因素. 科学通报, 2007, 52(增刊 I ) : 78-85.]

[ 6 ] Jin Qiang, Zhu Guangyou, Wang Juan. Deposition and distribution of high-potential source rocks in saline lacustrine environments. Journal of China University of Petroleum: Edition of Natural Science, 2008, 32(4): 19-23. [ 金强, 朱光有, 王娟. 咸化湖盆优质烃源岩的形成与分布. 中国石油大学学报: 自然科学版, 2008, 32(4) : 19-23.]

[ 7 ] Peng Ping'an, Qin Yan, Zhang Hui et al. Kinetics of kerogen transformation by heating in closed system. Marine Origin Petroleum Geology, 2008, 13(2) : 27-36. [彭平安, 秦艳, 张辉等. 封闭体系有机质与有机碳氢氮恢复动力学研究. 海相油气地质, $2008, \mathbf{1 3}(2): 27-36$. ]

[ 8 ] Zheng Rongcai, Liu Meiqing. Study on palaeosalinity of Chang-6 oil reservoir set in Ordos Basin. Oil \& Gas Geolog, 1999, 20(1) : 20-25. [郑荣才, 柳梅青. 鄂尔多斯盆地长 6 油层组古盐度研究. 石油与天然气地质, 1999, 20 (1) : 20-25. ] 
[ 9 ] Wang Changyong, Zheng Rongcai, Liu Zhe et al. Paleosalinity of Chang 9 reservoir in Longdong area, Ordos Basin and its geological significance. Acta Sedimentologica Sinica, 2014, 32(1) : 159-165. [王昌勇, 郑荣才, 刘哲等. 鄂尔多斯盆. 地陇东地区长 9 油层组古盐度特征及其地质意义. 沉积学报, 2014, 32(1) : 159-165.]

[10] Liu Jiang, Zheng Rongcai, Gou Xingfu et al. Analysis of paleosalinity from member 8 oil layer of Yanchang formation in Zhenyuan area, Ordos Basin, China. Journal of Chengdu University of Technology: Science \& Technology Edition, 2015, 42(3) : 354-360. [刘䧈, 郑荣才, 苟幸福等. 鄂尔多斯盆地镇原地区长 8 油层组古盐度分析. 成都理工大学学报: 自然科学版, 2015, 42(3): 354-360.]

[11] Shi Zhensheng, Xie Wuren, Ma Shiyu et al. Transgression sedimentary records of the members 4-6 of upper Triassic Xujiahe formation in Sichuan Basin. Journal of Palaeogeography, 2012, 14(5): 583-595. [施振生, 谢武仁, 马石玉等. 四 川盆地上三叠统须家河组四段一六段海侵沉积记录. 古地理学报, 2012, 14(5) : 583-595.]

[12] Wang Jintao. Who said the Qinghai lake will turn into Lop Nur. People’s Daily, 2015.9.28, 016 edition. [王锦涛. 谁说青 海湖会成罗布泊. 人民日报, 2015.9.28, 第 016 版.]

[13] Wang Xinmin, Song Chunhui, Shi Yongmin et al. Modern sedimentary and sedimentary facies characteristics in Qinghai lake. Acta Sedimentologica Sinica, 1997, 15 (Supp) : 157-162. [王新民, 宋春晖, 师永民等. 青海湖现代沉积环境与 沉积相特征. 沉积学报, 1997, 15(增刊) : 157-162.]

[14] Sun Jianchu. Qinghai lake. Geological Review, 1938, 3 (5): 507-512. [孙健初. 青海湖. 地质论评, 1938, 3( 5): 507-512.]

[15] Shi Yongmin, Dong Pu, Zhang Yuguang et al. Revelation of modern deposits in Qinghai lake to precise exploration of lithologic hydrocarbon reservoirs. Natural Gas Industry, 2008, 28(1):54-57. [师永民, 董普, 张玉广等. 青海湖现代沉 积对岩性油气藏精细勘探的启示. 天然气工业, 2008, 28(1): 54-57.]

[16] Zheng Mianping, Xiang Jun eds. Salline lakes on the Qinghai-Xizhang( Tibet) plateau. Beijing: Beijing Science and Technology Press, 1989: 9-28. [郑绵平, 向军. 青藏高原盐湖. 北京: 北京科学技术出版社, 1989: 9-28.]

[17] Ling Zhiyong, Li Tingwei, Wang Jianping et al. A review on the saline sedimentation and environmental evolution of Tibet plateau in recent 20 years. Earth and Environment, 2014, 42(1):25-33. [凌智永, 李廷伟, 王建萍等. 近 20 年来青 藏高原盐湖沉积与环境演化研究综述. 地球与环境, 2014, 42(1) : 25-33.]

[18] Yan JP, Hinderer M, Einsele G. Geochemical evolution of closed-basin lakes: general model and application to Lakes Qinghai and Turkana. Sedimentary Geology, 2002, 148(1/2) : 105-122. DOI: 10.1016/S0037-0738(01)00212-3.

[19] Deng Miao, Wang Ling, Lin Jinhui. Characteristics of micro-crystal muscovite in west sichuan, China: an X-ray powder diffraction analysis. Acta Mineralogica Sinica, 2006, 26(2): 131-136. [邓苗, 汪灵, 林金辉. 川西微晶白云母的 X 射 线粉晶衍射分析. 矿物学报, 2006, 26(2): 131-136.]

[20] Ye Jinhua, Zhu Meixi, Ding Xiaochen et al. A research of Kerogen preparation methods. Experimental Petroleum Geloog, 1983, 5(4): 321-325. [叶金华, 朱美茜, 丁晓晨等. 干酪根制备方法的研究. 石油实验地质, 1983, 5(4): 321-325.]

[21] Study Group of Institute of Soil Science, Chinese Academy of Sciences. Soil and phosphate rock of guano in South China Sea Islands. Soil, 1976, (3) : 125-131. [中国科学院南京土壤研究所考察组. 南海诸岛土壤和鸟粪磷矿. 土壤, 1976, (3): 125-131.]

[22] Zhao Sanping, Sun Liguang, Liu Xiaodong et al. Using Sr / Ca and Mg / Ca ratios as source indicators of ornithogenic lacustrine sediments on coral island. Quaternary Sciences, 2007, 27(1): 150-155. [赵三平, 孙立广, 刘晓东等. $\mathrm{Sr} / \mathrm{Ca}$, $\mathrm{Mg} / \mathrm{Ca}$ : 珊瑚岛鸟粪沉积的物源指示计. 第四纪研究, 2007, 27(1) : 150-155.]

[23] Lanzhou Institute of Geology, Chinese Academy of Sciences ed. A comprehensive survey report on the Qinghai Lake. Beijing: Science Press, 1979: 44-165. [中国科学院兰州地质研究所. 青海湖综合考察报告. 北京: 科学出版社, 1979: 44-165. ]

[24] Durand B ed. Kerogen-insoluble Organic Matter from Sedimentary Rocks. Paris: Editions Technip, 1980: 519.

[25] Huang Difan, Li Jichao. X-diagram of kerogen classification and the characters of kerogen of standard humic type. Geochimica, 1982, 11(1): 21-30. [黄第藩, 李晋超. 干酪根类型划分的 X 图解. 地球化学, 1982, 11(1): 21-30.]

[26] Chen Yicai, Shen Zhongmin, Luo Xiaoping eds. Petroleum \& gas organic geochemistry. Beijing: Science Press, 2007: 1856. [陈义才, 沈忠民, 罗小平. 石油和天然气有机地球化学. 北京: 科学出版社, 2007: 18-56.]

[27] Xu Hai, Liu Xiaoyan, An Zhisheng et al. Spatial pattern of modern sedimentation rate of Qinghai Lake and a preliminary 
estimate of the sediment flux. Chin Sci Bull, 2010, 55(4/5) : 384-390. [徐海, 刘晓燕, 安芷生等. 青海湖现代沉积 速率空间分布及沉积通量初步研究. 科学通报, 2010, 55(4/5) : 384-390.]

[28] Li Shanying, Yu Bingsong, Dong Hailiang. Study on organic matters in the sediments from the bottom of the Qinghai lake, China. Petroleum Geology \& Experiment, 2006, 28(4) : 375-379. [李善营, 于炳松, Dong Hailiang. 青海湖湖底沉积 物中的有机质. 石油实验地质, 2006, 28(4) : 375-379.]

[29] Huang Difan. Characteristics and geological significance of organic matters in the sediments of modern lakes. Geology Geochemistry, 1981, 5: 25-36. [黄第藩. 现代湖泊沉积物中有机质的特征及其地质意义. 地质地球化学, 1981, 5: 25-36.]

[30] Zhang Zhihuan, Yang Fan, Li Dongming et al. The organic geochemistry research progress in Cenozoic salified lake in China. Advances in Earth Science, 2000, 15(1): 65-69. [张枝焕, 杨藩, 李东明等. 中国新生界咸化湖相有机地球化学 研究进展. 地球科学进展, 2000, 15(1): 65-69.]

[31] Frenzel P, Wrozyna C, Xie M et al. Palaeo-water depth estimation for a 600-year record from Nam Co (Tibet) using an ostracod-based transfer function. Quaternary International, 2010, 218: 157-165. DOI: 10.1016/j.quaint.2009.06.010.

[32] Wang Minfang, Jiao Yangquan, Ren Jianye et al. Method and thinking of palaeogeomorphologic reconstruction in sedimentary basin-example from depositional stage of Xishanyao formation in Junggar Basin. Xinjiang Geology, 2006, 24(3) : 326330. [王敏芳, 焦养泉, 任建业等. 沉积盆地中古地貌恢复的方法与思路一以准噶尔盆地西山窑组沉积期为例. 新疆地质, 2006, 24(3): 326-330.]

[33] Wan Jinfeng, Xian Benzhong, She Yuanqi et al. Palaeobathymetric reconstruction based on natural Gamma Ray spectrometry logging data—by taking Bachu formation in region 4 of Tahe oilfield for example. Journal of Oil and Gas Technology ( $J$. $J P I), 2011,3(6)$ : 98-103. [万锦峰, 鲜本忠, 余源琦等. 基于伽马能谱测井信息的古水深恢复方法一一以塔河 油田 4 区巴楚组为例. 石油天然气学报 (江汉石油学院学报) , 2011, 3(6) : 98-103.]

[34] Jiang Zhenglong, Deng Hongwen, Lin Huixi et al. Methods and applicati on of paleo-geom or phologies rebuilding: an example of the second member of Shahejie formation, Zhuangxi area, Jiyang depression. Geoscience, 2009, 23 (5): 865871. [姜正龙, 邓宏文, 林会喜等. 古地貌恢复方法及应用一以 以济阳坳陷桩西地区沙二段为例. 现代地质, $2009, \mathbf{2 3}(5)$ : 865-871.]

[35] Immenhauser A. Estimating palaeo-water depth from the physical rock record. Earth-Science Reviews, 2009, 96: 107-139. DOI : $10.1016 /$ j.earscirev.2009.06.003.

[36] Pang Xiongqi, Chen Zhangming, Chen Fajing eds. Numerical simulation of hydrocarbon generation, remaining and expulsion of source rocks in geohistory and their quantitative evalution. Beijing: Geological Publishing House, 1993: 97-135. [ 庞雄奇, 陈章明, 陈发景. 含油气盆地地史、热史、生留排烃史数值模拟研究与烃源岩定量评价. 北京: 地质出版 社, 1993: 97-135.]

[37] Tissot BP. Premiers donnees surles mecanismes et al cinetiquede formation dupetroledans les sediments: simulation dunschema reactionnel sur ordinateur. Revue de Institut Francaisdu Petrole, 1969, 24: 470-501.

[38] Ungerer P, Pelet R. Extrapolation of the kinetics of oil and gas formation from laboratory experiments to sedimentary Basins. Nature, 1987, 327: 52-54.

[39] Xiao Lihua, Meng Yuanlin, Gao Daling et al. A new calculation method for hydrocarbon generation and discharge amount in geochemical logging. Petroleum Geology and Experiment, 1998, 20(1): 98-102. [肖丽华, 孟元林, 高大岭等. 地化 录井中一种新的生、排烃量计算方法. 石油实验地质, 1998, 20(1) : 98-102.]

[40] Wang Jie, Chen Jianfa. Restoration on organic matter abundance of carbonate source rocks: a case of middle-upper Proterzoic carbonate rocks in north China. Natural Gas Geoscience, 2004, 15(3): 306-310. [王杰, 陈践发. 关于碳酸盐岩 烃源岩有机质丰度恢复的探讨: 以华北中、上元古界碳酸盐岩为例. 天然气地球科学, 2004, 15(3) : 306-310.]

[41] Chen Zengzhi, Hao Shisheng. Mathematical simulation of the effect of hydrocarbon discharge on the hydrocarbon productivity in kerogen. Journal of China University of Petroleum, 1991, 15(6) : 7-14. [陈增智, 郝石生. 排烃效率对于酪根累 计产烃率影响的数学模拟. 石油大学学报 (自然科学版), 1991, 15(6): 7-14.]

[42] Lu Shuangfang, Xue Haitao, Zhong Ningning et al. Simulating calculation of the variations of organic matter abundance and hydrocarbon-generating potential during geological processes. Geological Review, 2003, 49(3): 292-297. [ 卢双舫, 薛海涛, 钟宁宁等. 地史过程中烃源岩有机质丰度和生烃潜力变化的模拟计算. 地质论评, 2003, 49(3): 292-297. ] 
[43] Zhong Ningning, Lu Shuangfang, Huang Zhilong et al. TOC changes in the process of thermal evolution of source rock and its controls. Science in China: Series D, 2004, 34(Supp I ) : 120-126. [ 钟宁宁, 卢双舫, 黄志龙等. 烃源岩生烃演化 过程 TOC 值的演变及其控制因素. 中国科学: D 辑, 2004, 34(增刊 I ) : 120-126.]

[44] Xiong Guoqing, Jiang Xinsheng, Wu Hao. A new method to estimate original or ganic carbon in the marine argillaceous source rocks according to Mo-TOC correlation: an example from the Cretaceous marine mudstones and shales in southern Xizang. Sedimentary Geology and Tethyan Geology, 2010, 30(2): 66-72. [熊国庆, 江新胜, 伍告. 用 Mo-TOC 相关性 估算海相泥质烃源岩原始有机碳的一种新方法一以藏南白严系海相泥岩、页岩为例. 沉积与特提斯地质, $2010,30(2): 66-72$.

[45] Lu Shuangfang, Liu Xiaoyan, Qu Jiayan et al. Restoring of original hydrocarbon potential and original organic carbon of source rocks in Huhehu depression, Hailar Basin. Journal of Daqing Petroleum Institute, 1995, 19(1) : 31-34. [ 卢双舫, 刘晓艳, 曲家燕等. 海拉尔盆地呼和湖凹陷烃源岩原始生烃潜力和原始有机碳的恢复. 大庆石油学院学报, 1995, $19(1): 31-34$.

[46] Li Jijun, Wu Hui, Lu Shuangfang et al. Development and hydrocarbon expulsion efficiency of source rock in 9th member of Yanchang formation, Ordos Basin. Journal of Jilin University: Earth Science Edition, 2012, 42(Supp1): 26-32. [李吉 君, 吴慧, 卢双舫等. 鄂尔多斯盆地长 烃源岩发育与排烃效率. 吉林大学学报: 地球科学版, 2012, 42(增刊 1): 26-32.] 